\title{
Far from easy and accurate - detection of metabolic syndrome by general practitioners
}

\author{
Eeva-Eerika Helminen ${ }^{1,2}$, Pekka Mäntyselkä*2,3, Irma Nykänen³ and \\ Esko Kumpusalo 2,3
}

\author{
Address: ${ }^{1}$ Kuopio Health Centre, Kuopio, Finland, ${ }^{2}$ Family Practice Unit, Kuopio University Hospital, Kuopio, Finland and ${ }^{3}$ School of Public \\ Health and Clinical Nutrition, University of Kuopio, Kuopio, Finland \\ Email: Eeva-Eerika Helminen - eeva-eerika.helminen@fimnet.fi; Pekka Mäntyselkä* - pekka.mantyselka@uku.fi; \\ Irma Nykänen - irma.nykanen@uku.fi; Esko Kumpusalo - esko.kumpusalo@uku.fi \\ * Corresponding author
}

Published: 30 November 2009

BMC Family Practice 2009, 10:76 doi:10.1 186/1471-2296-10-76

This article is available from: http://www.biomedcentral.com/I47/-2296/10/76

(c) 2009 Helminen et al; licensee BioMed Central Ltd.

This is an Open Access article distributed under the terms of the Creative Commons Attribution License (http://creativecommons.org/licenses/by/2.0), which permits unrestricted use, distribution, and reproduction in any medium, provided the original work is properly cited.
Received: 12 June 2009

Accepted: 30 November 2009

\begin{abstract}
Background: Metabolic syndrome (MetS) is a major public health challenge. General practitioners (GPs) could play a key role in its recognition. However, it often remains undiagnosed in primary care. This study assesses how well GPs and patients recognise MetS among patients with coronary heart disease or at least one of its risk factors.

Methods: Twenty-six health centres around Finland were randomly selected for the purpose of identifying, over a two-week period in April 2005, patients meeting the inclusion criteria of coronary heart disease or one of its risk factors. GPs and identified patients $(n=1880)$ were asked to complete surveys that included a question about the patient's MetS status. A trained nurse conducted health checks $(n=1180)$ of the identified patients, utilising criteria of MetS modified from the National Cholesterol Program. Data from the GPs' survey were compared with those from the health check to establish the extent of congruence of identification of MetS.

Results: Almost half (49.4\%) of the patients met the criteria of MetS as established by objective measures. However, in the GPs' survey responses, only $28.5 \%$ of the patients were identified as having MetS. Additionally, these groups of MetS patients were not congruent. The sensitivity of the GPs' diagnosis of MetS was 0.31 with a specificity of 0.73 . Only $7.1 \%$ of the study patients stated that they were suffering from MetS.
\end{abstract}

Conclusion: Detection of MetS is inaccurate among GPs in Finland. Most patients were not aware of having MetS. The practical relevance of MetS in primary care should be reconsidered.

\section{Background}

Because of the epidemic of overweight and sedentary lifestyle, the prevalence of metabolic syndrome (MetS) is increasing worldwide [1], and the syndrome has become a major public health challenge [2]. General practitioners
(GPs) play a key role in recognising MetS, but it is rarely recorded as a diagnosis in clinical practice [3]. Despite several efforts to make diagnosis feasible for clinicians, the syndrome often remains undiagnosed in primary health care [4]. 
During the last decade, various medical organizations have published their criteria of metabolic syndrome [5]. However, only the two most recent definitions are suitable for the primary care framework. In 2001 the National Cholesterol Education Program (NCEP) published a working definition of the syndrome based on five commonly measured clinical criteria that physicians could implement in their practices [6]. In 2005 the International Diabetes Federation (IDF) released their set of criteria of MetS [7]. The IDF definition provides a stepwise approach to risk, with measurement of the waist as a simple initial screening test followed by assessment of four other components.

Finland has been a pioneer in promoting the concept of MetS since the beginning of the nineties [8]. The leading domestic professional journal for doctors in Finland first published articles about this topic in 1992 [9]. MetS has been represented in the Finnish Physician's Handbook since 1996 [10]. The Handbook has portrayed MetS as a risk factor of cardiovascular diseases and has described the epidemiology and clinical features of MetS. The Finnish version of ICD-10 has had a code for MetS (E66.00) since 1999. Moreover, since the early 2000s, there has been a steady stream of information about MetS for GPs, provided mainly by specialists and pharmaceutical companies. Based on these efforts and scientific literature, MetS can be considered to constitute a very common and important risk factor of diabetes and cardiovascular diseases. This means primary care physicians should have the most important role in detecting and treating MetS. However, it remains unclear to what extent MetS is recognised by GPs.

In this study we examined how well GPs recognise MetS among patients with coronary heart disease (CHD) or at least one of its risk factors (previously diagnosed diabetes or metabolic syndrome, hypertension, smoking or dyslipidaemia). We compared these results with the actual percentage of patients meeting the criteria of MetS according to modified NCEP criteria (Table 1). We also established the extent to which the patients themselves were aware that they had MetS.

\section{Methods \\ Participants}

The Heart 2005 study was carried out in 26 randomly selected primary care health centres around Finland that represented the entire Finnish public primary care system in terms of size and location. Altogether 181 general practitioners collected the data during two workweeks in April 2005. The study was a descriptive cross-sectional study, and it was approved by the Ethics Committee of Kuopio University Hospital and the University of Kuopio.

The patients included in the study had to have CHD or at least one of its risk factors, such as previously diagnosed diabetes or metabolic syndrome, hypertension, smoking or dyslipidaemia. A patient was considered to have CHD if it had been diagnosed by a doctor or it was indicated by a specific code on the patient's health insurance card. The study doctors made records of CHD and the risk factor status of each patient. All the patients who visited the health centre during the two weeks and met the study criteria were registered and invited to attend a health check conducted by a trained nurse.

From the regular patient stream, 1880 patients were identified as meeting the inclusion criteria of the study. Written informed consent to participate in the study was given by 1331 of them. Altogether 1208 filled in the patient questionnaire and 1180 of them attended the health check. Thus, the participation rate was $62.8 \%$. The basic characteristics and measurements of the study patients are shown in Table 2.

The GPs collecting the patient data were mainly senior doctors, and $67.5 \%$ of them had over 10 years of work experience. The average age of female doctors was 42 years and of male doctors, 47 years. There was a slight predominance of female doctors (56.1\%).

\section{Data collection}

At the health check, after a five-minute rest the nurse measured the patient's blood pressure twice with an interval of a few minutes, using a cuff fitting the patient's upper arm circumference. The mean of the measurements was used in analysing the results. The nurse recorded the latest

Table I: Heart 2005 study criteria of metabolic syndrome according to modified National Cholesterol Education Program criteria.

\footnotetext{
Metabolic syndrome is present when three or more of the five criteria are met.

I. impaired glucose tolerance (IGT), increased fasting plasma glucose (IFG) or diabetes (DM)

2. hypertension $\geq 140 / 90 \mathrm{mmHg}$ or medication for hypertension

3. serum triglyceride concentration $\geq 1.7 \mathrm{mmol} / \mathrm{l}$

4. reduced serum $\mathrm{HDL}$ cholesterol $<1.2 \mathrm{mmol} / \mathrm{l}$ for women and $<1.0 \mathrm{mmol} / \mathrm{l}$ for men

5. waist circumference $>88 \mathrm{~cm}$ for women and $>102 \mathrm{~cm}$ for men.
}

HDL, high density lipoprotein. 
Table 2: Basic characteristics of I I 60 Heart 2005 study subjects.

\begin{tabular}{|c|c|}
\hline Age (years) $n=1159$ & $63.8(1 \mathrm{I})$ \\
\hline$\geq 65$ years $(\%) n=1159$ & 53.9 \\
\hline $\operatorname{Sex}(\operatorname{men} \%) n=1135$ & 42.8 \\
\hline $\mathrm{BMI} n=1155$ & $29.7(5.1)$ \\
\hline Current smokers (\%) $n=1152$ & 16.4 \\
\hline Hypertension $(\%) n=1116$ & 73.8 \\
\hline Dyslipidaemia (\%) n = 1109 & 69.7 \\
\hline $\mathrm{CHD}(\%) \mathrm{n}=1080$ & 19.4 \\
\hline Diabetes (\%) $n=1083$ & 28.4 \\
\hline Fasting plasma glucose $(\mathrm{mmol} / \mathrm{l}) \mathrm{n}=1042$ & $6.15(1.5)$ \\
\hline $\mathrm{SBP}(\mathrm{mmHg}) \mathrm{n}=1 / 36$ & $144(19)$ \\
\hline $\mathrm{DBP}(\mathrm{mmHg}) \mathrm{n}=1135$ & $84(10)$ \\
\hline Total cholesterol $(\mathrm{mmol} / \mathrm{l}) \mathrm{n}=1085$ & $5.11(1.0)$ \\
\hline Triglycerides $(\mathrm{mmol} / \mathrm{l}) \mathrm{n}=1050$ & $1.47(0.80)$ \\
\hline HDL cholesterol, men $(\mathrm{mmol} / \mathrm{l}) \mathrm{n}=437$ & $1.3(0.38)$ \\
\hline HDL cholesterol, women $(\mathrm{mmol} / \mathrm{l}) \mathrm{n}=599$ & $1.6(0.47)$ \\
\hline Waist circumference, men $(\mathrm{cm}) \mathrm{n}=465$ & $105(12)$ \\
\hline Waist circumference, women $(\mathrm{cm}) \mathrm{n}=63 \mathrm{I}$ & $95(14)$ \\
\hline
\end{tabular}

BMI, body mass index; CHD, coronary heart disease; SBP, systolic blood pressure; DBP, diastolic blood pressure; HDL, high density lipoprotein.

Figures are means (SD) unless stated otherwise.

laboratory results of haemoglobin, total serum cholesterol, HDL and LDL cholesterol and triglycerides as well as fasting plasma glucose and Hb-A1c values. If these tests had not been conducted during the last 12 months, the patient was sent to the laboratory. The nurse also measured the patient's height, weight and waist circumference.

The patients agreeing to take part in the study were asked to fill in a questionnaire. One question asked whether the patient had ever been diagnosed with or treated for metabolic syndrome, with the possible answer being "yes" or "no". The GPs filled in a doctor's questionnaire about every patient registered for the study, and again one question asked whether the patient had metabolic syndrome, the answer being either "yes" or "no".

The criteria of metabolic syndrome used in the study were given in the doctor's questionnaire (Table 1). The criteria followed the NCEP definition [6], with some modifications. Impaired glucose tolerance and diabetes were added to the first criterion. There was a higher threshold value for hypertension and the use of antihypertensive medication was included in the second criterion. Also, the cut-off values were slightly lower for HDL cholesterol. These modifications were made according to the criteria of MetS in the Finnish Physician's Handbook 2004 [11]. The threshold value used for increased fasting plasma glucose was $\geq 5.6 \mathrm{mmol} / \mathrm{l}$.

The data collected in the patient's questionnaire, in the doctor's questionnaire and at the health check were used to analyse how many of the patients met the study criteria of MetS. The laboratory results collected at the health check were used to determine whether the patient met each criterion according to the threshold values indicated in Table 1. The patient was considered to have diabetes if the question "Have you been diagnosed with diabetes?" was answered positively or if the doctor had replied positively to the question whether or not the patient had diabetes. The patients were also asked "Have you undergone an oral glucose tolerance test (OGTT)?" The possible answers were (1) "no", (2) "yes, my blood glucose levels were normal", and (3) "yes, my blood glucose levels were above normal". The patient was considered to have IGT if the third option was chosen.

\section{Statistical analysis}

The results are expressed as frequencies. The sensitivity and specificity of the GPs' diagnosis of metabolic syndrome were calculated. All statistical analyses were performed using SPSS statistical software for Windows, version 16.0 .

\section{Results}

The GPs had answered the question about metabolic syndrome in 1173 (99.4\%) of the 1180 patient cases. They assessed that $28.5 \%$ of the study patients $30.7 \%$ of the men, $27.4 \%$ of the women) had MetS according to the study criteria. However, $49.4 \%$ of the patients $(50.8 \%$ of the men, $49.6 \%$ of the women) met the study criteria of metabolic syndrome according to the measurements and records made at the nurse's appointment and the answers from the patients' questionnaires. The measurements and records were collected appropriately from 1160 (98.3\%) of the 1180 study patients, as $20(1.7 \%)$ individuals had to be excluded due to missing data. Moreover, the group of patients with MetS according to the GPs' evaluation did not quite match with the group of patients actually meeting the study criteria of the syndrome. The sensitivity of the general practitioners' diagnosis for MetS was 0.31 and the specificity was 0.73 (Table 3 ).

Of the 1180 patients, 1059 (89.7\%) had answered the question about whether they had been diagnosed with or treated for metabolic syndrome. In 75 (7.1\%) cases the answer was positive. Of the patients reporting having MetS, $53(70.7 \%)$ met the study criteria, as opposed to 466 subjects $(48.2 \%)$ in the group reporting that they did not have the syndrome.

\section{Discussion}

In our study, MetS was poorly detected by general practitioners; the sensitivity of diagnosis was only 0.31 . Much work has been done during the last 15 years to familiarise GPs with the syndrome, but it seems that it is still unrecognised. On the other hand, the fact that only $75(7.1 \%)$ 
Table 3: Metabolic syndrome reported by general practitioners versus patients meeting the study criteria of metabolic syndrome in the Heart 2005 study $(n=1153)$.

\begin{tabular}{|c|c|c|c|c|}
\hline \multirow{4}{*}{ Patients meeting the study criteria of MetS $(n=1160)(\%)$} & & \multicolumn{2}{|c|}{ MetS reported by GPs $(n=1173)(\%)$} & \multirow[b]{3}{*}{570} \\
\hline & & Yes & No & \\
\hline & \multirow{2}{*}{$\begin{array}{c}\text { yes } \\
\text { no }\end{array}$} & $176(30.9)$ & $394(69.1)$ & \\
\hline & & $157(26.9)$ & $426(73.1)$ & 583 \\
\hline & & 333 & 820 & 1153 \\
\hline
\end{tabular}

MetS, metabolic syndrome; GPs, general practitioners

out of 1059 patients reported having MetS suggests that the condition is even more unclear to patients.

It can be considered quite alarming that the GPs did not recognise MetS in patients meeting the criteria of the syndrome. However, there may be valid reasons for this. For example, over the years there have been several different definitions of MetS, which may well have confused rather than helped GPs in diagnosing the syndrome. We did not use as strict a definition of MetS as actual NCEP criteria. Further, some of the patients might have had IGT, resulting in more cases of MetS. Hence, the real proportion of patients with MetS could have been slightly higher. However, the definition of MetS used in the present study is comparable with the definition that was used in Finnish primary care during the study period.

Our study was conducted during the hectic everyday routine in the primary care setting. This may have affected the accuracy of MetS detection by the GPs. Nonetheless, these are the real working conditions in a GP's office. MetS has been promoted as a simple public health care strategy for doctors to identify patients at high risk [12]. If it does not work in real-life conditions, such as in the bustle of a GP's office, then it will not meet its original aim.

There might be several reasons why GPs are not using the diagnosis of MetS. Firstly, over the years more and more counter-arguments have been raised about the diagnostic, prognostic and therapeutic value of MetS [13-15]. Secondly, differing and even contradictory [15] statements from various expert organizations have been announced. On top of that, there are already several tools for identifying apparently healthy individuals at an elevated risk of diabetes, such as the glucose tolerance test $[16,17]$ and the diabetes risk score [18], or of CVD, such as the Framingham risk score [19] or the SCORE model [20]. As the time reserved for a GP's appointment is limited, it is not realistic to assume that several risk assessment models would be used in evaluating one patient.

How is MetS going to survive in this battle of prevention strategies, and more importantly, what is the future role of MetS? Metabolic syndrome is not likely to replace cur- rently used global risk scoring algorithms, so both traditional risk factors and emerging metabolic markers associated with metabolic syndrome should be incorporated in future risk assessment systems [21]. The need for such global risk evaluation tools is emphasized even more as waist circumference and waist-to-hip ratio have been shown to be strongly associated with death [22]. In a busy primary care clinical practice, this could mean a computerized decision support system that would be integrated into electronic patient records. This would enable the physician to make risk assessments based on a single algorithm without any particular scoring systems.

A cohesive and clear message is urgently needed from the scientific community to clarify how MetS and other risk evaluation models should be used in primary care.

\section{Conclusion}

Detection of MetS is inaccurate among GPs in Finland. Most patients were not aware of having MetS. The practical relevance of MetS in primary care should be reconsidered.

\section{Competing interests}

The authors declare that they have no competing interests.

\section{Authors' contributions}

E-EH performed the statistical analysis, participated in the design of the study and drafted the paper. PM participated in the design of the study and helped in drafting the manuscript. IN participated in the design of the study and helped in drafting the manuscript. EK conceived the study and participated in the design of the study and helped in drafting the manuscript. All authors read and approved the final manuscript.

\section{Acknowledgements}

The authors would like to thank all the participants and health professionals who contributed their time and effort to this study in health centres around Finland. The study was approved by the Ethics Committee of Kuopio University Hospital and the University of Kuopio. The study was supported by a grant number $\mathbf{8 7 5 6}$ from MSD through Kuopio University Hospital. The researchers were independent of this funding. All authors declare no conflict of interest. 


\section{References}

I. World Health Organization: Report of a WHO consultation, Obesity: preventing and managing the global epidemic. Geneva: World Health Organization; 2000.

2. Zimmet P, Alberti KG, Shaw J: Global and societal implications of the diabetes epidemic. Nature 200I, 4I 4:782-787.

3. Ford EF, Rarer than a blue moon: The use of a diagnostic code for the metabolic syndrome in the US. Diabetes Care 2005, 28:1808-1809.

4. Bo S, Ciccone G, Pearce N, Merletti F, Gentile L, Cassader M, Pagano G: Prevalence of undiagnosed metabolic syndrome in a population of adult asymptomatic subjects. Diabetes Res Clin Pract 2007, 75:362-365.

5. Laakso M, Kovanen PT: Metabolic syndrome: To be or not to be? Ann Intern Med 2006, 38:32-33.

6. Executive summary of the third report of The National Cholesterol Education Program (NCEP): Expert panel on detection, evaluation, and treatment of high blood cholesterol in adults (Adult Treatment Panel III). JAMA 200I, 285:2486-2497.

7. Alberti KG, Zimmet P, Shaw J: The metabolic syndrome: a new world-wide definition. Lancet 2005, 366:1059-1062

8. Ilanne-Parikka P, Eriksson JG, Linström J, Hämäläinen $H$, KeinänenKiukaanniemi S, Laakso M, Louheranta A, Mannelin M, Rastas M, Salminen V, Aunola S, Sundvall J, Valle T, Lahtela J, Uusitupa M, Tuomilehto J, Finnish Diabetes Prevention Study Group: Prevalence of the metabolic syndrome and its components: findings from a Finnish general population sample and the Diabetes Prevention Study Cohort. Diabetes Care 2004, 27:2 I 35-2I 40.

9. Kuusisto J, Laakso $\mathrm{M}$ : [Hypertension and insulin resistance]. Suomen Lääkärilehti 1992, 33:3II4. (in Finnish)

10. Vanhala M: [Classification of hyperlipidemias]. In [Physician's Handbook] Edited by: Kunnamo I. Helsinki, Duodecim Medical Publications Ltd; 1996:676-677. (in Finnish)

II. Vanhala M: [Metabolic syndrome]. In [Physician's Handbook] Edited by: Kunnamo I. Helsinki, Duodecim Medical Publication Ltd; 2004:786-787. (in Finnish)

12. Alberti KG, Zimmet PZ: Should we dump the metabolic syndrome? No. BMJ 2008, 336:64I.

13. Reaven GM: The metabolic syndrome: requiescat in pace. Clin Chem 2005, 5 I:931-940.

I4. Gale E: Should we dump the metabolic syndrome? Yes. BMJ 2008, 336:640.

15. Kahn R, Buse J, Ferranninni E, Stern M: The metabolic syndrome: time for a critical appraisal. Joint statement from the American Diabetes Association and the European Association for the Study of Diabetes. Diabetologia 2005, 48: I684- I699.

16. Stern MP, Williams K, Haffner SM: Identification of persons at high risk for type 2 diabetes mellitus: do we need the oral glucose tolerance test? Ann Intern Med 2002, I 36:575-58 I.

17. McNeely MJ, Boyko EJ, Leonetti DL, Kahn SE, Fujimoto WY: Comparison of a clinical model, the oral glucose tolerance test, and fasting glucose for prediction of type $\mathbf{2}$ diabetes risk in Japanese Americans. Diabetes Care 2003, 26:758-763.

18. Lindstrom J, Tuomilehto J: The diabetes risk score: a practical tool to predict type 2 diabetes risk. Diabetes Care 2003, 26:725-73।.

19. D'Agostino RB Sr, Grundy S, Sullivan LM, Wilson P: Validation of the Framingham coronary heart disease prediction scores: results of a multiple ethnic groups investigation. JAMA 200I, 286: $180-187$.

20. Scheltens T, Verschuren WM, Boshuizen HC, Hoes AW, Zuithoff NP, Bots ML, et al.: Estimation of cardiovascular risk: a comparison between the Framingham and the SCORE model in people under 60 years of age. Eur J Cardiovasc Prev Rehabil 2008, I 5:562-566.

21. Arsenault BJ, Pibarot P, Després JP: The quest for the optimal assessment of global cardioavascular risk: are traditional risk factors and metabolic syndrome partners in crime? Cardiology 2008, I I 3:35-49.

22. Pischon T, Boeing H, Hoffmann K, Bergmann M, Schulze MB, Overvad K, Schouw YT van der, Spencer E, Moons KG, Tjønneland A, Halkjaer J, Jensen MK, Stegger J, Clavel-Chapelon F, Boutron-Ruault MC, Chajes V, Linseisen J, Kaaks R, Trichopoulou A, Trichopoulos D, Bamia C, Sieri S, Palli D, Tumino R, Vineis P, Panico S, Peeters PH, May AM, Bueno-de-Mesquita HB, van Duijnhoven FJ, Hallmans G, Weinehall L, Manjer J, Hedblad B, Lund E, Agudo A, Arriola L, Barricarte A,
Navarro C, Martinez C, Quirós JR, Key T, Bingham S, Khaw KT, Boffetta $P$, Jenab $M$, Ferrari $P$, Riboli E: General and abdominal adiposity and risk of death in Europe. NEJM 2008, 359:2 105-2I 20.

\section{Pre-publication history}

The pre-publication history for this paper can be accessed here:

http://www.biomedcentral.com/1471-2296/10/76/pre pub
Publish with Biomed Central and every scientist can read your work free of charge

"BioMed Central will be the most significant development for disseminating the results of biomedical research in our lifetime. "

Sir Paul Nurse, Cancer Research UK

Your research papers will be:

- available free of charge to the entire biomedical community

- peer reviewed and published immediately upon acceptance

- cited in PubMed and archived on PubMed Central

- yours - you keep the copyright

Submit your manuscript here:

http://www.biomedcentral.com/info/publishing_adv.asp
BioMedcentral 